\title{
ATIVIDADE MINERADORA E TRANSPORTE MARÍTIMO DE LONGO CURSO: CONTRIBUIÇÕES PARA A ANÁLISE DA INTEGRAÇ̃̃O INTERNACIONAL DA AMAZÔNIA PARAENSE PELA PERSPECTIVA DA RENDA.
}

\author{
Alegria LEITE ${ }^{1}$ \\ Daniel SOMBRA ${ }^{2}$ \\ Carlos CASTRO 3 \\ Mateus LOBATO ${ }^{4}$
}

\section{RESUMO}

Este artigo apresenta contribuições para a análise da lógica de reprodução da atividade mineral e de navegação marítima por meio da renda diferencial, identificando os elementos presentes na configuração desses dois setores conexos. A indústria mineral estabelecida na Amazônia paraense tem característica primário-exportadora, logo ainda depende de mercados internacionais para dar sentido ao valor de uso das riquezas presentes nesse território. Nesse sentido, busca-se identificar as ferramentas teóricas adequadas para a elaboração de uma metodologia para aferir a renda diferencial neste setor. Para tal, é preciso considerar o setor de transportes. Após considerar os elementos relevantes, tece-se conclusões para a elaboração da metodologia em questão.

Palavras-chave: Renda diferencial; mineração; sistema de transportes.

\section{ABSTRACT}

This article presents contributions to analysis of the reproduction logic of mineral activity and shipping through the theory of differential rent, identifying the elements present in the configuration of these two related sectors. The mineral industry established in the Paraense Amazon has primary-export feature, then still dependent on international markets to make sense your value of these riches in territory.In that sense, we seek to identify appropriate theoretical tools for the development of a methodology for get the differential income in this sector. To do that, is necessary to consider the transportation sector. After considering the relevant factors, it weaves up conclusions about the development of the methodology in question.

Keywords: differential income; mining; transport system.

\footnotetext{
${ }^{1}$ Doutoranda em Desenvolvimento Econômico, Território e Meio Ambiente pelo Programa de PósGraduação em Economia da Universidade Federal do Pará (PPGE-UFPA). Bacharela em Economia pela Universidade Federal do Pará (UFPA). Bacharela em Administração com ênfase em Gestão Pública pelo Instituto Federal de Ciência, Tecnologia e Educação do Pará (IFPA). Bacharela em Administração com ênfase em Gestão Empresarial pela Universidade da Amazônia (UNAMA). E-mail: alegria1717@gmail.com

${ }^{2}$ Geógrafo do Núcleo de Meio Ambiente da Universidade Federal do Pará (NUMA-UFPA). Mestre em Geografia pelo Programa de Pós-Graduação em Geografia da Universidade Federal Fluminense (POSGEO-UFF). E-mail: dsombra@ufpa.br

${ }^{3}$ Professor da Universidade do Estado do Pará (UEPA). Doutorando em Geografia pelo Programa de PósGraduação em Geografia da Universidade Federal do Pará (PPGEO-UFPA). E-mail: carlosjorge319@gmail.com

${ }^{4}$ Professor da Secretaria de Estado de Educação do Pará (SEDUC-PA). Doutorando em Geografia pelo Programa de Pós-Graduação em Geografia da Universidade Estadual Paulista Campus Presidente Prudente (PPGEO-UNESP-PRUDENTE). E-mail: mateusmonteirolobato@gmailc.om
} 


\section{INTRODUÇÃO}

A atividade mineradora propicia benefícios aos proprietários na forma de renda auferida no desenvolvimento da atividade. Muito embora a renda da terra seja uma categoria pouco estudada pela teoria econômica, a noção de renda mineral apresenta especificidades que merecem atenção, uma vez que sua natureza está ligada à exauribilidade de sua fonte. O objetivo deste trabalho é apresentar o conceito de renda na literatura econômica, principalmente no que se refere à forma Diferencial I e II, o que implica em adentrar no campo dos transportes, bem como tratar das especificidades da renda dos recursos minerais no estado do Pará baseado na mineração do ferro, corroborando com a hipótese de que a renda da terra se converte num instrumento primordial de repartição do mais valor nas regiões periféricas num padrão de acumulação de exportação especialização produtiva.

O Pará, em menos de sete décadas, se tornou o segundo maior produtor mineral do Brasil, estando atrás somente de Minas Gerais que já desenvolve a mineração há mais de três séculos. Aproximadamente $88 \%$ dos 15,8 bilhões de dólares oriundos das exportações totais do Pará em 2013 se devem à indústria da mineração e transformação mineral, o que torna o setor mineral o carro chefe das exportações paraenses, sendo que somente o ferro corresponde a 70,7\% do total das exportações (MDIC, 2013).A indústria extrativa mineral respondeu por 40\% do PIB estadual em 2011 (IBGE, s. d.), enquanto que a cadeia mineral respondeu por 271 mil empregos diretos e indiretos em 2013, sendo que para cada emprego gerado na indústria mineral, criam-se outros treze postos de trabalho ao longo da cadeia produtiva (IBRAM, 2013). A arrecadação do royalty da CFEM aumentou 53\% em um ano (de 2012 para 2013), sendo Parauapebas e Canaã dos Carajás os dois municípios com o maior volume de arrecadação.

A mineração na Amazônia tem origem recente no âmbito das atividades produtivas no espaço nacional. A presença dos recursos minerais no território foi uma dádiva inexplorada até o período desenvolvimentista brasileiro. O quadro histórico no qual a região amazônica foi articulada ao território nacional, modificando sua inserção na dinâmica global de acumulação capitalista teve a atividade mineradora como um de seus pilares de sustentação. Este rearranjo espacial, que reconfigurou as formas pelas quais se manteve a dependência e o subdesenvolvimento no estrado do Pará, exigiu modificações no sistema de objetos regional, principalmente no que tange à base logística para a viabilização dos fatores econômicos, conectando estoque de recursos 
primários ao mercado consumidor, conforme será abordado nas próximas sessões.

Destarte, o trabalho se estrutura, além deste proêmio, numa breve revisão teórica solidificada em bases marxistas da análise do capital, transportes e renda da terra, seguida pela análise da questão da mineração e a especificidade dos transportes marítimos; seguido, por fim, das considerações finais.

\section{REFERENCIAL TEÓRICO}

O modo de produção capitalista gera contradições internas as quais, rotineiramente, irrompem sob a forma de crises. Para Harvey (2005), a análise marxiana conclui que certas tendências (concentração de capital inutilizado em um polo, derivando no excesso de liquidez, e concentração de trabalho inutilizado, em outro polo, derivando no desemprego estrutural) inerentes ao capitalismo produzem graves tensões no processo de acumulação. Para solucioná-las, o capital lança mão de estratégias que só podem ser, de fato, compreendidas reconhecendo as condições para o processo de acumulação, as quais, em suma, são: evidentemente, a existência da renda implica num decréscimo do lucro médio de uma formação espacial, mas sem afetar diretamente um capitalista específico (VERGOPOULOS, 1979). O trabalho que produzirá o valor que será repatriado sob a forma de renda se dá em qualquer ponto de uma formação espacial, e, por isto, a terra "se valoriza", mesmo que nela nada esteja se produzindo (MARTINS, 1986). Assim, o proprietário da terra cobra da sociedade inteira um tributo pelo uso de sua propriedade. Doravante, entende-se porque ao capital interessa a subsunção da renda da terra ao capital.

Diferente de Ricardo, Marx assevera que a renda diferencial II não provém do ciclo da natureza, mas da aplicação de capital em faixas de terra de igual fertilidade (PAULANI, s/d). Esta seria determinada pelo fluxo de capital investido no solo através de sistemas de objetos (irrigação, construções físicas etc.), resultando em maior volume produtivo por unidade. Em terras onde capital constante é investido, o preço individual de produção fica abaixo do preço regulador do produto (advindo da terra de pior fertilidade), permitindo a produção de um sobrelucro.Este caso assemelha-se ao caso normal de lucro extraordinário como diferença entre o preço individual de produção de uma mercadoria e o preço social de produção, derivado do tempo de trabalho socialmente necessário (TTSN).

Marx (1998) assegura, porém, que, em condições regulares, este sobrelucro é apropriado, sob a forma de renda diferencial, pelos proprietários fundiários em 
detrimento dos arrendatários capitalistas. Como fato derivado da natureza e acumulação do capital, a renda diferencial persistiria com a socialização do solo, mas seria revertida ao conjunto da sociedade (CARIO; BUZANELO, 1986). De acordo com Astarita (2010), os lucros extraordinários em capitais tecnologicamente avançados tendem a desaparecer com a generalização dos avanços tecnológicos, enquanto que a renda constitui um sobrelucro que proprietário de terras se apropria de modo perene. Entrementes, para Santos (1996), ainda que a globalização se traduza espacialmente na unicidade da técnica hegemônica, é da própria natureza do capital reproduzir espaços tecnologicamente desiguais.

Para Martins (1986), a conclusão marxiana indica que a apropriação da renda não se deve às diferenças entre solos, mas à realização da propriedade privada. A renda diferencial II evidencia a contradição entre arrendatários capitalistas e proprietários de terra. Nesta relação social, os últimos cedem aos primeiros o direito de aplicação de capital constante na propriedade, elevando a produtividade do trabalho. Porém, ao fim do ciclo, encontram-se em impasse, pois os últimos levam em consideração os rendimentos auferidos com a aplicação de capital constante, exigindo aumento da renda; ao passo que os primeiros exigem "contratos de arrendamento longos, para que possam, por mais tempo, apropriar como sobrelucro o valor excedente adicional obtido com os investimentos por eles realizados." (MARX, 1984, p. 166), reclamando a diminuição da mesma em face das benfeitorias efetuadas na propriedade.

Para Astarita (2013), a renda absoluta foi a forma que melhor Marx consegui provar sem infringir a teoria do valor-trabalho, apontando duas razões para a sua existência: $a$ ) o monopólio da propriedade da terra, e não as características físicoquímicas do solo; e, $b$ ) a interrelação entre os setores agrícola e industrial na formação e distribuição do valor em função da diferença na composição orgânica de capital (COC). Para este autor, a renda absoluta tende a desaparecer, uma vez que a colocação de Marx acerca da renda diferencial II indica que a terra se transforma em objeto de inversão de capitais como qualquer setor, o que implica no aumento da COC na agricultura em longo prazo, eliminando a diferença de COC entre indústria e agricultura.

Para Harvey (2008, p. 428), porém, Marx é consciente que “(...) a base legal nada decide e que toda a explicação da renda tem de tornar compatível um pagamento feito à terra com uma teoria do valor que se encontra no trabalho". Marx (1984), contudo, destaca que a diferença na COC advém da contraposição entre valor (resultante do TTSN) e preço (expressão monetária do valor), os quais podem ser 
diferentes uma vez que a concorrência entre capitais diversos (com diferentes COC) determina a taxa média de lucro entre os setores, derivando daí a conversão de valores em preços médios. Para além disso, a COC implica em distintas quantidades em valor de capital constante a capital variável. Logo, a existência da renda absoluta está condicionada ao aumento do preço da mercadoria em relação ao seu valor de produção, calculado com a taxa média de lucro da formação espacial.

Por fim, tem-se a renda de monopólio, a qual apesar de atribuída à mera propriedade requer condições ao processo de produção e distribuição, com a capacidade de realização do preço de monopólio. De fato, ela decorre da condição de caráter único, em termos de qualidade ou localização, de determinado espaço em relação ao mercado, conferindo a seu detentor a extração de rendas monopolistas. Isso está ligado à produção de bens excepcionais, bens cujos preços são determinados não pelo TTSN à sua produção, mas pela disposição a pagar de quem deseja adquirir tais bens, conforme o exemplo dos vinhos portugueses de Marx (1984). Tem-se aqui capital investido no direito de cobrar um tributo, uma parte da mais-valia global de uma formação espacial, sob a forma de renda.

\subsection{Subsídios para pensar a renda no setor mineral}

A princípio, a análise da renda pode iluminar um caminho metodológico para o estudo das relações que envolvem o setor mineral na Amazônia. Trindade et al (2013) levantam dados que mostram que uma grande sociedade anônima monopolista, controlada por um consórcio financeiro, investe crescentemente capital constante na composição técnica, objetivando maior produtividade e elevado ganho de mercado. Neste ínterim, para Trindade op cit, os transportes devem ser entendidos como parte da infraestrutura de circulação e do departamento determinante da intensidade da exploração (DI) do capital envolvido, pela justaposição da massa de capital constante envolvida nas operações de grande escala de transporte.

Neste sentido, os custos, entre os quais os transportes, afetam a COC. O capital empregado no sistema de objetos (logística terrestre, portuária e marítima) é fundamental em operações com mercadoria de baixo valor agregado. No circuito geral do fluxo do valor, as partes que se apropriam da produção tendem a conflitar com as que se apropriam da circulação, ainda que naquela esteja a origem do valor. Para Marx (1998, p. 166), “embora a indústria de transporte se apresente no regime de produção capitalista como causa dos custos de circulação, esse fenômeno particular em nada 
altera a substância da coisa". Harvey (2005) assevera que a circulação possui dois aspectos fundamentais: $a$ ) o movimento físico das mercadorias do lugar de produção ao de consumo; e, $b$ ) o custo real ou implícito ligado ao tempo consumido e às mediações necessárias (rede de atacadistas, varejistas, operações bancárias etc.) para que a mercadoria chegue ao consumidor.

Harvey (2005) pontua que o primeiro aspecto é integrante do processo produtivo, e, logo, gerador de valor (sempre através do trabalho), enquanto que o segundo é um custo necessário de circulação, não sendo gerador de valor. Seu pagamento ocorre com a dedução de parte do excedente exatamente conforme a renda da terra, nesse caso o valor (TTSN) para desempenhar alguma tarefa determinada. A valoração das próteses agregadas à terra nua já é aqui um processo conhecido; a valoração da terra nua e os pagamentos dela resultantes, no entanto, estão assente no processo que Vergopoulos (1977) nomeou mais-valia de transferência para explicar a renda. Harvey (2005) destaca que este pagamento ao mercado de terras não seria possível sem: $a$ ) troca generalizada de mercadorias; $b$ ) monetização da economia; e, $c$ ) a existência da propriedade privada.

Para Dussel (2012), nos Grundrisse, Marx elaborou um texto mais explicativo dessa derivação, no capitalismo, da renda da terra a partir do acúmulo de trabalho em uma formação. O direito normatizará e a ideologia e cultura moderna normalizará a inversão. Tal como o capital parecerá valorizar-se a si mesmo, a terra também o fará. O arranjo espacial é mediado pelo mercado fundiário/imobiliário, possibilitando a capacidade se apropriar desses pagamentos, os quais podem ter efeitos positivos ou negativos para a acumulação de capital, bem como há efeitos da localização e da fertilidade do solo em relação aos preços de produção (HARVEY, 2008). Neste ínterim, deve-se traçar um paralelo entre a fertilidade do solo na agricultura e a concentração de minerais em determinados solos.

Para a agricultura, os custos de produção e a taxa média de lucro das terras menos produtivas ditam o preço de mercado, enquanto as mais produtivas se beneficiam de sua condição econômica, se apropriando de maior excedente, ou melhor, possuem menores preços de produção em relação ao mercado (HARVEY, 2008). Na mineração, os capitais podem ser investidos na intensificação da exploração do trabalho nas minas, cujo exemplo clássico é o caso das minas de estanho da Patiño Mines na Bolívia nos anos 1930-1950 (CHIAVENATO, 1980), como no incremento de capita constante, com tecnologias de extração, logística e de modificações químicas, semelhantes às alternativas apontadas por Marx (1984) para a agricultura. Porém, conforme Dussel 
(2012), a mineração é um caso pouco explorado por Marx tanto nos Grundrisse, como n’O Capital, posto objetivava a enunciação das determinações da produção em geral.

Porém, nas oportunidades em que se referiu às minas de ferro e carvão na Inglaterra (MARX, 1984), e quanto ao ouro, explicando o valor do dinheiro a partir do trabalho nas minas (MARX, 2011), vê-se que o autor utiliza raciocínio semelhante ao aplicado à agricultura. Logo, tem-se na mineração a renda absoluta, cobrada da maisvalia global de determinada formação, em virtude da posse de minas; a renda diferencial I agregada às minas com maior quantidade e qualidade de minérios, bem como vantagens no que tange ao espaço relativo (sistema de transportes); e a renda diferencial II agregada às minas com maior quantidade aplicada de capital constante.

Para pensar o caso da mineração, faz-se importante notar ainda que, ao contrário de Marx (que o postulava apenas para a renda absoluta), Vergopoulos (1979) acredita que a renda diferencial II implica na diminuição do lucro médio de uma formação espacial. Vergopoulos (1979) mostra que os economistas clássicos (Malthus, Ricardo e Rodbertus) negaram a renda da terra enquanto extração de valor do trabalho, através do controle da propriedade, sendo que este valor não necessariamente foi produzido no solo ou na cultura sobre a qual a renda é cobrada. Tanto a renda da terra como os juros do crédito provêm de sequestros de mais-valia (MARX, 1984). Esta situação cria a contradição de que quem investe em capital constante na agricultura é penalizado em relação a quem nada investe nos solos apoiado na especulação.

Esta a razão de Marx (1984) afirmar ser sadia ao capitalismo a renda diferencial, a qual provém da competição entre os proprietários, enquanto a renda absoluta provém da pura extração de mais-valia do setor industrial. Mas, para Vergopoulos (1979), ambas extraem mais-valia de outros setores. A inversão em favor da indústria se deu com a expansão colonial, derivando na minimização da renda da terra no centro do capitalismo à custa da expansão da exploração agrícola sobre novas áreas do capitalismo (troca desigual entre setores e regiões produtivas). Assim, "a causa original da renda absoluta é o atraso relativo da agricultura em relação à indústria. Os proprietários fundiários não são, sob esta ótica marxista, quem se aproveita do atraso fundado sob uma composição orgânica do capital inferior à média -, captando os sobrelucros" (VERGOPOULOS, 1979, p.63). A aplicação ao caso empírico, porém, traz novos elementos à tona.

No caso da formação brasileira, por exemplo, o fato da renda diferencial I ter sido a força determinante do arranjo espacial, o converteu em sinônimo da própria lei 
dos rendimentos decrescentes. Isto porque, conforme Moreira (2015, p. 40) "a renda diferencial de localização determina o ponto local da ocupação do espaço. E a renda diferencial de fertilidade, o ponto ideal da localização, consideradas as distintas alternativas de possibilidade. Nem sempre o lugar posicional assim escolhido é o de melhor localização e solo fértil, contudo. De modo que a lei do arranjo é a que melhor contemple a combinação dessas necessidades". O fato, porém, é que a monocultura é uma atividade extensiva em capital, e que rapidamente esgota o recurso solo, forçando uma permanente mobilidade. Em certo momento não há alternativa a não ser o incremento de capital constante.

No caso do Brasil agrícola, "sendo uma economia de exportação, busca-se a localização mais próxima do porto marítimo, onde seja menor o custo de deslocamento" (MOREIRA, 2015, p. 40). O prolongamento dessa situação exige uma mudança na forma de extração de valor. Porém, a forma da manutenção do poder político nacional persistia rentista. Em um primeiro momento baseada na extração de mais-valia absoluta do estoque de trabalho, às vezes extração de formato pré-capitalista; mas, em segundo momento, modificado para a extração de mais-valia relativa. No primeiro se fazia necessário manter no espaço de produção colonial um tempo e espaço de reprodução da força de trabalho, com produção doméstica de valores de uso, o que já não ocorre quando há a intermediação de valores de troca para cumprir esse papel de barateamento do fator trabalho (OLIVEIRA, 1977). De qualquer modo, produção e circulação se entrechocam e interrelacionam neste processo histórico. Conforme Moreira (2015, p. 41):

A ocupação colonial dá-se inicialmente nos núcleos vicentino, baiano e pernambucano. E, neles, nas várzeas dos rios, à beira da linha marítima da localização portuária. Na Bahia e em Pernambuco, onde com o tempo a economia canavieira se concentra, frente o fracasso da experiência vicentina, a altíssima fertilidade do massapé compensa o problema da localização, cada vez mais interiorizada, resolvendo-se o problema com a abertura de portos, à beira do rio e chamando para aí a localização do canavial e do engenho. $\mathrm{O}$ tempo foi afastando, todavia, os centros de produção dessa combinação sololocalização apropriada, num adentramento vale acima, rio adentro, de custos crescentes. [...] Agrava o problema agora, porém, o encarecimento da lenha, dado o rápido desaparecimento da mata. O salto para o Sudeste vai encontrar o mesmo movimento de itinerância e conflito de relação fertilidadelocalização com a lavoura cafeeira. A monocultura é empurrada das áreas de fertilidade mediana das cercanias litorâneas da cidade do Rio de Janeiro e das encostas fluminense, mineira e espírito-santense do valo do Paraíba para as de altíssima fertilidade da terra roxa e do bauru superior presentes no planalto paulista, numa compensação da localização absolutamente distante do porto marítimo. Com o tempo, assim como na área canavieira dos solos de massapé da zona da mata nordestina, a renda diferencial puxa a monocultura para localizações distantes e solos menos férteis, a lei do rendimento decrescente empurrando a cafeicultura para localizações e solos cada vez mais distantes 


\section{Alegria LEITE; Daniel SOMBRA; Carlos CASTRO; Mateus LOBATO}

da costa e custos mais altos. Isso gera um conflito de leis espaciais que o cafeicultor tentará sanar com a substituição do transporte de burros por meios modernos de transferência (transportes, comunicações e transmissão de energia), buscando burlar com a tecnologia da era urbano-industrial a regência da renda diferencial I, passando-a para a diferencial II, porém numa continuidade da monocultura, o tropeço condenado por Waibel.

Neste ínterim, modifica-se por completo o arranjo espacial, na medida em que o arranjo espacial molecular de localização e fertilidade da renda diferencial I é substituído pelo arranjo dos circuitos de áreas de produção especializada, estando estas acopladas a circuitos internacionais de circulação da renda diferencial II, sendo este um período de espaços monopolistas (MOREIRA, 2015), correspondendo à era dos grandes monopólios. Transportar tal análise para uma atividade monopolizada internacionalmente em uma grande fronteira de recursos como a Amazônia implica em considerar na devida medida este jogo de escalas. Por outro lado, para Vergopoulos (1979, p. 64), "se a renda absoluta representa perda de ganho para a taxa de lucro industrial, a renda diferencial é mais temível, pois consiste numa transferência nítida [de mais-valia] da indústria para a agricultura”. E, conforme Harvey (2005), a indústria dos transportes gera valor, mas o transporte, como capital fixo, cobra o seu custo tanto renda diferencial I, como diferencial II.

Se Vergopoulos (1979) estiver correto, a renda diferencial poderia significar uma transferência de valor da indústria para a mineração. Porém, ao se considerar uma fonte de minérios mais distante de seu principal mercado consumidor em relação a potenciais concorrentes, o que se tem é a renda diferencial dos transportes consumindo parte dos lucros da indústria mineral. Evidentemente, o plano teórico apresentado ilustra possibilidades, mas a análise do fenômeno em estudo de caso se mostra bem mais complexa. Com o advento do capital monopolista já não se trata de competição entre minas, mas entre grandes monopólios.

É provável que, neste nível, a renda diferencial II seja a mais adequada para a passagem ao nível da totalidade, uma vez que a renda diferencial I obtida por minas particulares já influi cada vez menos à escala dos monopólios globais. Ainda assim, tal só pode ser afirmado a partir da análise detalhada do setor. A renda diferencial I, na passagem à escala global, deve focar nas distâncias não entre minas, mas entre as diversas formações espaciais. Para tal o melhor recurso, provavelmente, é a análise do setor de circulação marítima pelo qual flui a produção mineral. 


\section{ANÁLISE DO SETOR MINERAL A PARTIR DA RENDA DIFERENCIAL}

Do ponto de vista operacional, a renda diferencial é a diferença entre o preço de mercado e os custos de produção. Então, as piores minas determinam o preço de mercado, enquanto as minas mais produtivas, através da intensificação tecnológica de exploração e incremento da rotação do capital, conseguem capturar essa diferença na realização da mais-valia relativa. É provável que por mina deva-se entender companhia mineral. Isso dá a possibilidade de grandes empresas mineradoras inverter capital em atividades auxiliares do seu processo produtivo, como o controle de meganavios graneleiros. O controle pode ser realizado pela conversão da mineradora em armador, quer seja pela encomenda de navios graneleiros, quer seja pelo afretamento a casco nu dessas embarcações.

No Brasil, o crescimento da frota tem sido retomado por meio de programas nacionais de incentivo à indústria naval. Contudo, isso não significa que as construções para emprego em embarcações do tipo bulk carrier $^{5}$ sejam realizadas em território amazônico ou brasileiro. A indústria naval mais competitiva está situada nos países asiáticos, responsáveis por pelo menos $80 \%$ da produção mundial em termos de toneladas de porte bruto em comparação com a indústria naval brasileira (KUBOTA, 2013). Há 34 estaleiros para fabricação de embarcações off-shore, mas apenas dois na região amazônica existem apenas dois (SINAVAL, 2013), sendo que dos projetos encomendados na Amazônia, não há navios de grande capacidade, projetados para longo curso na modalide bulk carrier, tais como os que compõe o índice do Baltic Exchange Dry Index.

O mercado de afretamento mundial de embarcações ainda sofre de excesso de capacidade, devido à crise de 2008 e, em consequência disso, muitos armadores de grande capacidade enfrentam receitas abaixo dos custos operacionais. Segundo a UNCTAD (2013), os fretes declinaram de US\$ 200.000/dia para menos de US\$ 50.000/dia no mercado tramp do segundo semestre de 2007 até final de 2013. Mas no que tange ao ordenamento territorial, nos termos do capítulo II, artigo 20 e inciso IX da Constituição Federal, os "recursos minerais, inclusive o subsolo" são bens públicos da União, de maneira que a exploração destes bens se dá mediante prévia autorização de

5 Navio mercante, especialmente desenhado para o transporte de carga sem qualquer tipo de embalagem ou invólucro, geralmente em porões, para materiais desagregados. 
órgãos competentes (BRASIL, 2004). Esse órgão é o Departamento Nacional da Produção Mineral (DNPM).

A mineração do ferro é realizada pela companhia Vale S.A., uma das maiores produtoras mundiais de minério de ferro e pelotas, produzindo também níquel, manganês, ferro ligas, cobre, carvão térmico e metalúrgico, fosfatados, potássio, cobalto, caulim e metais do grupo da platina (PGMs) e outros produtos, estando presente na exploração mineral de 24 países. No Brasil a empresa opera em um grande sistema de engenharia o qual inclui ferrovias, terminais e um porto marítimo, integrados às suas operações de mineração. Por intermédio de afiliadas e de joint ventures, possui grandes investimentos no setor energético (como participações em hidrelétricas, produção de biocombustíveis e aço). A empresa também opera em três sistemas na produção e distribuição de Ferro no país, quais sejam: sistemas Norte, Sul e Sudeste. Sendo que há total integração entre os sistemas Norte e Sudeste, os quais consistem de minas, ferrovias, terminais marítimos e instalações portuárias. O Sistema Sul consiste de três minas e dois terminais marítimos.

A mineração do ferro, no Sistema Norte, data de 1985, está localizado em Carajás, no estado do Pará, e contém uns dos maiores depósitos de minério de ferro do mundo. As reservas estão divididas em norte, sul e leste. O Sistema Norte possui minas a céu aberto e uma usina de processamento de minério. As minas estão localizadas em terras públicas para as quais a empresa obteve licenças de exploração. Devido ao do elevado teor $(66,7 \%$, em média) dos depósitos do Sistema Norte, não é necessário operar uma planta de concentração em Carajás. O processo de beneficiamento consiste apenas de operações de medição, peneiramento, hidrociclonagem, britagem e filtragem. Após isto o minério de ferro é transportado pela Estrada de Ferro de Carajás (EFC) até o terminal marítimo de Ponta da Madeira, no estado do Maranhão. No ano de 2010 a produção em milhões de toneladas métricas de ferro no Pará ficou em torno de 101,2 milhões de toneladas métricas, segundo o Relatório Vale - produção no exercício em 31 de dezembro de 2010.

A demanda de produtos derivados do ferro é influenciada por vários fatores, como a produção global de manufaturas, a construção civil e os gastos com infraestrutura. Em 2010, a China respondeu por 42,9\% dos embarques de minério de ferro e pelotas e a Ásia, como um todo, por 60,7\%. A Europa respondia por 20,7\%, seguida o mercado interno nacional com $13,7 \%$. Atualmente a China é o maior parceiro comercial brasileiro, com quem, em 2013, o Brasil comercializou o volume de US\$ 83 
bilhões, enquanto que com o Mercosul, o montante foi de US\$ 43,8 bilhões. O setor de transportes vislumbra uma parceria sino-brasileira na consecução de investimentos no Brasil em logística, tanto em exportação quanto em importação (STREIT, 2014).

O mercado de minério de ferro é altamente competitivo, sendo que os principais fatores que afetam a concorrência são: $a$ ) o preço; $b$ ) a qualidade; $c$ ) a confiabilidade; $d$ ) os custos operacionais; e, e) os custos de transporte. Os maiores concorrentes no mercado asiático estão localizados na Austrália e incluem subsidiárias e afiliadas da BHP Billiton e Rio Tinto Ltda. Apesar destas empresas gozarem da renda diferencial I no que tange à localização, rebaixando os cursos de circulação, a Vale mantém a competitividade no mercado asiático devido ao fato das empresas siderúrgicas procurarem em geral obter tipos (ou misturas) de minério de ferro que possibilitem fabricar o produto final desejado da maneira mais econômica e eficaz.

As jazidas do Carajás têm baixos níveis de impurezas e outras propriedades que costumam resultar em custos mais baixos de processamento (reduzido consumo de coque e elevada produtividade nos altos-fornos). E em períodos de elevada demanda a qualidade torna-se mais importante para os clientes do que o diferencial de transporte. Outro fato é a garantia às siderúrgicas de fornecimento garantido de um mix específico de minério de ferro, dado à integração logística da atividade. É interessante observar a questão do espaço relativo quando se faz a comparação entre os diversos produtores. É ressaltada a distância em dias de cada produtor do mercado consumidor chinês: "O Brasil está a 40 dias da China, a 10 dias da Austrália, a 15 dias da Índia, e a 30 dias da África do Sul" (BAHIAMERCANTIL, 2014). Nisso se observa a importância de capturar a renda diferencial I e II, pela aplicação de capital tanto na inversão em suas tecnoestruturas de transporte quanto de intensificação da lavra de minérios de ferro (TRINDADE, [s.d.]).

Em relação à Vale, observa-se em seus relatórios financeiros, os ciclos de inserção logística, são os de maior importância, sendo que "do total de minério de ferro e outros produtos transportados, $28 \%$ foi para terceiros e $72 \%$ foi para nós mesmos" (VALE, 2010, p. 189). As operações de logística concentram investimentos, como a EFC, em que a VALE dispõe de um contrato de concessão de 30 anos renováveis, com validade até 2027. A principal carga da ferrovia é o ferro. A EFC tem capacidade diária de 313.970 toneladas de minério de ferro. Somente no ano de 2010, transportou um total 
de 90,4 bilhões TKU ${ }^{6}$ de minério de ferro e outras cargas, dos quais, 3,0 bilhões TKU de carregamentos transportados para clientes, inclusive minério de ferro para clientes brasileiros. A EFC também transportou 341.583 passageiros em 2010.

A EFC possui o trem de maior capacidade na América Latina, que mede $3,4 \mathrm{~km}^{2}$ de comprimento e um peso bruto de 42.300 toneladas, quando carregado, possuindo 330 vagões. Outros investimentos destinam-se a portos e terminais marítimos como meio de completar a entrega do ferro e pelotas de minério de ferro a cargueiros a granel que atendem ao mercado transoceânico, com um porto e seis terminais. A empresa possui investimentos no setor energético, com a finalidade de reduzir custos de energia e minimizar o risco de problemas desse abastecimento de energia. Em 2010 a capacidade instalada no Brasil era de 818 MW. É importante observar que os fretes da navegação de longo curso também são compostos de custos referentes ao carregamento e descarregamento de navios. Entre eles, há atividades de apoio portuário desempenhado pelos rebocadores. Neste estudo não estão sendo considerados o declínio desses custos pela inversão em rebocadores e os efeitos na indústria naval nacional pela encomenda desses navios, apesar de conhecidas as atividades da mineradora Vale nesse sentido (FERREIRA; CRISTINA, 2011).

\subsection{Fretes marítimos e ciclos de navios}

Os ciclos de navios ${ }^{7}$ dizem muito a respeito de como os proprietários e afretadores decidem sobre os investimentos, baseando-se na demanda de transportes presente e futura, incorrendo em riscos, por exemplo, como proprietário de frota própria ou como tomador de recursos para construção e afretamento time charter, através de contratos de construção e transferência de propriedade para terceiros. Esses terceiros serão os responsáveis pela operação e terão a tarefa de gerenciar para que os custos de operação sejam inferiores aos avençados nos contratos de prestação de serviço de transporte, de onde devem vir seus rendimentos (STOPFORD, 1997).

No Brasil, o ordenamento do tráfego aquaviário é estabelecido pela Lei nº 9.432 de 1997, que define os critérios e conceitos, bem como as relações comerciais entre proprietários e empresas de navegação brasileiras e estrangeiras (BRASIL, 1997). Entre os conceitos importantes está a questão da propriedade de uma embarcação. Cada país

6 Toneladas por quilômetro útil.

7 Para um detalhamento melhor dos ciclos, conferir Stopford (1997, p. 43). 
possui regras para esse registro, que incluem vantagens e mais ou menos interferência do Estado, seja através de tributos à atividade ou restrições de ordem operacional. Os navios ore carriers também têm seu registro como meio de autenticar sua propriedade no Tribunal Marítimo, onde também são registrados os contratos de afretamento. Os contratos podem ser de diversas modalidades (definidas no art. $2^{\circ}$, incisos I à III): $a$ ) afreamento a casco nu; $b$ ) afretamento por viagem; e, $c$ ) e afretamento por tempo. Cada tipo possui uma relação apropriada aos negócios entre proprietário e armador.

Atualmente, as embarcações estão cada vez mais especializadas em operações de determinadas cargas, e, por isso, cada navio é construído e especificado segundo sua destinação. Para a finalidade de indústria mineral interessa estudar os orebulk carriers. Os principais serviços oferecidos pelos armadores são as linhas regulares (liners) e os serviços não regulares (tramp). Nos primeiros as rotas são preestabelecidas pelos armadores, enquanto nos segundos, os armadores gerenciam seus navios para captar os fretes onde for mais conveniente. Neste caso, tornam-se mais sensíveis às variações do comércio internacional. Essa modalidade é a mais adequada para afretamento de navios completos. Isso significa também que em linhas não regulares, os armadores-locatários têm a facilidade de ajustar sua capacidade de transporte de acordo com o fluxo comercial internacional de mercadorias. A composição do frete inclui os custos de embarque, desembarque e transporte. De acordo com os serviços incluídos há uma modalidade de contratação.

A quantidade de capital constante necessário para movimentar o volume de iron ore foi crescente com a explosão da demanda dos principais compradores de bens minerais do Pará, caso da China (com 56 milhões de ton.), Japão (13 milhões de ton.) e Alemanha (7,9 milhões de ton.), no ano de 2013 (BRASIL, 2013). A realização do valor é uma etapa imprescindível sem a qual o capitalismo está fadado ao fracasso, e na busca dessa realização depende de sua constante expansão, e como qualquer expansão, na busca de novos mercados, os custos de realização do ciclo capitalista perpassam pelos custos de transporte incorridos nessa busca pela realização. Conforme Marx (1988, p. 168):

O modo capitalista de produção diminui os custos de transportes para cada mercadoria com o desenvolvimento dos meios de transporte e de comunicação, com concentração (a magnitude da escala) do transporte. Aumenta a parte do trabalho social vivo e materializado, aplicada no transporte de mercadorias, primeiro transformando a grande maioria dos produtos em mercadorias e, segundo, substituindo mercados locais por mercados longínquos. 
Nesse sentido, a constante revolução dos meios de transporte pode ser acompanhada pela tecnologia e a revolução nos navios do tipo bulk carrier. A capacidade desses navios é medida em toneladas $\left(\mathrm{dwt}^{8}\right)$ e essa escala crescente de capacidade tem ditado os ganhos de escala nas operações de transporte de minérios para os mercados longínquos. O mercado de fretes marítimos para bulk materials pode ser acompanhado diariamente pela Baltic Exchance Index (BDI), que é uma composição de índices de preço dos fretes marítimos por tipo de navio. As categorias levam em consideração as dimensões das embarcações possíveis: Handymax, Capesize, Panamax e Valemax ${ }^{9}$.

\subsection{A questão do frete marítimo na indústria mineral}

O BDI "pode ser visto como um índice de preço de equilíbrio de custo de transporte de materiais brutos, determinado pela oferta de navios de carga e a demanda de transporte desses materiais nesse modal" (GHIORGHE; GIANINA, 2013, p. 4). Além disso, também são sensíveis às mudanças na demanda por materiais brutos como o iron ore, e os preços do óleo, logicamente porque os fretes estão simbioticamente ligados aos combustíveis empregados nesse transporte. A composição de preços dos minérios pode ser repartida entre os custos produtivos e improdutivos, sendo o primeiro relacionado à facilidade com que as minas são exploradas, assim, segundo levantamento do BNDES, o minério de ferro brasileiro contido nas minas da região Norte, no relatório da companhia Vale S.A. possui um teor de aproximadamente $66 \%$ de concentração.

Destarte, as usinas guseiras chinesas podem fazer a redução da hematita em ligas de ferro com qualidade superior aos demais fornecedores das quais a China importa, tal como os países da África e Austrália. Por outro lado, entre os principais custos improdutivos está a distância diretamente proporcional aos custos de transportes associados à realização dessa produção mineral em mercados longínquos. As grandes mineradoras têm base de grandes aparatos logísticos associados ao capital produtivo da mineração, dado que a comercialização de minérios é preponderantemente realizada por meios de transporte de larga escala, dado o baixo valor agregado das mercadorias. Entende-se que uma das formas de conexão entre as duas atividades, de transporte e de mineração, é a possibilidade de transformação da renda diferencial I e II em

8 Deadweight tonnage - toneladas de peso morto (livre tradução dos autores).

9 Dry bulk e iron ore, Capesize: 100,000 dwt plus; Panamax, 60,000-99,999 dwt; Handymax, 40,00059,999 dwt; Handysize, 10,000-39,999 dwt; Valemax, 400,000 dwt. 
investimentos que melhoram a logística e retroalimentam a capacidade de diminuir os custos de transporte e, em consequência, apropriação de mais renda diferencial entre o preço de produção e o preço de mercado.

\section{CONSIDERAÇÕES FINAIS}

A frota marítima de longo curso brasileira e seu aparato ainda está em transformação. A indústria naval foi reativada com as encomendas e nacionalização de produção, principalmente para a tank carriers. Porém, a revitalização para bulk carriers ainda é incipiente. Mesmo com recente operação de embarcações próprias e afretadas da Companhia Vale ainda conta com a produção fora das fronteiras nacionais. Diante desse cenário, parte da mais-valia gerada pela comercialização das commoditites minerais é subsumida através dos fretes marítimos pagos a armadores estrangeiros, seja pelo afretamento a casco nu, seja pela locação de serviços de transporte em que não envolvam a gestão comercial das embarcações.

A atividade minerária converte a renda da terra em mais-valia (pela transferência do valor da formação espacial), pela reaplicação da renda diferencial I e II para consecução de ampliações em suas tecnoestruturas de logística que permitam capturar mais renda. Os fluxos de insumos dispendidos na circulação do capital não revertem em atividades realizadas dentro do território nacional e apenas pressupõem uma posição confortável para a União através do balanço de pagamentos, deixando a Amazônia apenas com o ônus das operações minerárias em seu território e inexpressiva capacidade de efeitos multiplicadores de emprego e renda, dada não internalização dos demais ciclos associados de industrialização verticalizados que estão ausentes.

A estrutura de propriedade mantém o ciclo de apropriação das rendas na concentração de poucos e não se reverte da forma esperada em desenvolvimento econômico que habilite esses territórios em novas atividades produtivas após a exaustão desses recursos naturais. No entanto, este tem sido o arranjo espacial o qual permite a reprodução do status quo, num pacto de classes que vincula organicamente novas e velhas elites no comando do território. Razões extra-econômicas devem explicá-lo.

Desta forma, apesar da navegação marítima de longo curso ter papel preponderante na ligação entre os mercados de produção e consumo produtivo em escala mundial, ainda é incipiente a participação da frota brasileira no controle desses fretes. O embate de integração perpassa pela disputa entre os grandes players da 
mineração, quanto à exploração da renda da terra proporcionada pelas qualidades únicas do teor de minérios na Amazônia e os investimentos que essas rendas diferenciadas tomam nas decisões estratégicas de transporte que viabilizem a competição de sítios distantes dos mercados consumidores, através de tecnologias navais e de organização da produção. Finalmente, ainda que incipiente o desenvolvimento que internalize a maisvalia em termos de inversão em frotas nacionais e desenvolvimento das cadeias de logística e suas indústrias acessórias principalmente na Amazônia, para o Brasil tem sido essencial a participação na balança comercial dessas exportações e a ajuda na manutenção do equilíbrio no balanço de pagamentos.

\section{REFERÊNCIAS BIBLIOGRÁFICAS}

AMIN, Samir. "O capitalismo e a renda fundiária: a dominação do capitalismo sobre a agricultura". In: AMIN, Samir; VERGOPOULOS, Kostas. A questão agrária e o capitalismo. Tradução: Beatriz Resende. $2^{a}$ ed. Rio de Janeiro: Paz e Terra, 1977, pp. 9-42.

ASTARITA, Rolando. Economía política de la dependencia y el subdesarrollo: tipo de cambio y renta agraria en la Argentina.Bernal: Universidad Nacional de Quilmes, 2010.

BAHIAMERCANTIL. Entidade chinesa quer sanções contra frota de navios da Vale. Disponível em: <http://www.bahiamercantil.com.br/?p=1169\#\&panel1-2>. Acesso em: 21/08/2014.

BRASIL. Constituição da República Federativa do Brasil de 1988. Disponível em: http://www.planalto.gov.br/ccivil_03/constituicao/constituicao.htm

BRASIL. Lei n. 9.432 de 8 de janeiro de 1997.

BRASIL. MINISTÉRIO DE DESENVOLVIMENTO, INDÚSTRIA E COMÉRCIO EXTERIOR.Exportação por estado: sistema aliceweb. Disponível em: <http://www.desenvolvimento.gov.br/sitio/>. Acesso em: 04/09/2013.

CARIO, F. Silvo Antônio; BUZANELO, E. J. Notas sobre a teoria marxista da renda da terra. In: Revista de Ciências Humanas, v. 5, n. 8, p. 32-47, 1986.

DNPM. DEPARTAMENTO NACIONAL DE PRODUÇÃO MINERAL. Sumário mineral $e$ anuário mineral brasileiro. Brasília: DNPM, 2013.

DUSSEL, Enrique. A produção teórica de Marx: um comentário ao Grundrisse. Tradução: José Paulo Netto. São Paulo: Expressão Popular, 2012.

FERREIRA, M.; CRISTINA, F. Vale receives biggest ore carrier in the world. S/d. Disponível em: <http://saladeimprensa.vale.com/en/releases/interna.asp?id=20663>. Acesso em: $23 / 08 / 2014$.

GHIORGHE, C.; GIANINA, B. The dynamics of the dry bulk sub-markets. In: Journal of Knowledge Management, Economics and Information Technology, dez. 2013.

HARVEY, David. A produção capitalista do espaço. Tradução: Carlos Szlak. $2^{\mathrm{a}}$ edição. São Paulo: Annablume, 2005. 


\section{Alegria LEITE; Daniel SOMBRA; Carlos CASTRO; Mateus LOBATO}

HARVEY, David. Os limites do Capital. São Paulo: Boitempo, 2008.

IBGE. INSTITUTO BRASILEIRO DE GEOGRAFIA E ESTATÍSTICAS. Contas nacionais trimestrais. Indicadores por unidade da federação. Disponível em: <http://www.ibge.gov.br/home/estatistica/indicadores/pib/defaultcnt.shtm>. Acesso em 12/ $11 / 2014$.

IBRAM. INSTITUTO BRASILEIRO DE MINERAÇÃO. Informativo do Instituto Brasileiro de Mineração. Brasília: IBAM, 2013.

KUBOTA, Luís Cláudio. Indústria naval: um cenário dos principais players mundiais. Brasília: IPEA, 2013.

MARTINS, S. José de. Os camponeses e a política no Brasil: as lutas sociais no campo e seu lugar no processo político. $3^{\mathrm{a}}$ ed. Petrópolis: Vozes, 1986.

MARX, Karl. O Capital:crítica da economia política. Livro III, tomo I. São Paulo: Abril Cultural, 1984.

MARX, Karl. O Capital: crítica da economia política. Livro II. Civilização Brasileira, 1998.

MARX, Karl.Grundrisse: manuscritos econômicos de 1857-1858: esboços da crítica da economia política. Tradução: Mario Duayer, Nélio Schneider. Rio de Janeiro: Boitempo, 2011.

MOREIRA, Ruy. Geografia, teoria e crítica. Petrópolis: Vozes, 1982.

MOREIRA, Ruy. Sociedade e espaço geográfico no Brasil: constituição e problemas de relação. $1^{\text {a }}$ Ed. $1^{a}$ Reimp. São Paulo: Contexto, 2015.

OLIVEIRA, Francisco de. A economia da dependência imperfeita. $2^{\text {a }}$ Ed. Rio de Janeiro: Graal, 1977.

PAULANI, Leda Maria. Acumulação e Rentismo: resgatando a teoria da renda de Marx para pensar o capitalismo contemporâneo. S. d. Disponível em: $<$ http://www.fea.usp.br/feaecon/media/fck/File/Acumulacao\%20e\%20Rentismo\%20(Sem.\%20I PE).pdf >. Acessado em: 12/12/2014.

SANTOS, Milton. Técnica, espaço, tempo: globalização e meio técnico-científico informacional. $2^{a}$ Ed. São Paulo: Hucitec, 1996.

SINAVAL. Mapa de Estaleiros. Disponível em: <http://www.sinaval.org.br/docs/Mapa_EstaleirosBrasil.pdf>. Acesso em: 20/08/2014.

STOPFORD, M. “The shipping market cyle". In: GROUP, T. \& F. (Org.). Maritime Economics. $2^{a}$ Ed. London: Routledge, 1997, pp. 37-75.

STREIT, R. Trocas comerciais entre Brasil e China batem recorde em 2013. Disponível em: <http://www.cnt.org.br/Paginas/Agencia_Notici.aspx?notiica=trocas-comerciais-brasil-china12052014>. Acesso em: 20/08/ 2014.

TRINDADE, J. R. B. Capital monopolista e renda mineral na Amazônia: condicionalidades e contradições contemporânas. Cadernos CEPEC, 2013. Disponível: http://www.ppgeconomia.ufpa.br/documentos/Espaco\%20agrario\%20julho13\%20revista\%20C EPEC\%20V.2\%20N.8.pdf

UNCTAD. Review of Maritime Transport 2013. Disponível em: <http://unctad.org/en/publicationslibrary/rmt2013_en.pdf>. Acesso em: 21/08/2014.

VALE. Relatório 20F. Disponível em: <http://www.vale.com/PT/investors/Quarterly-results- 
reports/20F/20FDocs/20F_2012p.pdf >. Acesso em: 23/09/2014.

VERGOPOULOS, Kostas. "O capitalismo disforme: o caso da agricultura no capitalismo". In: AMIN, Samir; VERGOPOULOS, Kostas. A questão agrária e o capitalismo. Tradução: Beatriz Resende. $2^{\text {a }}$ Ed. Rio de Janeiro: Paz e Terra, 1977, pp. 43-179.

WANG, J. et al. China Shunning Ships Shows \$2.3 Billion Vale Mistake: Freight. Disponível em: <http://www.bloomberg.com/news/print/2011-11-23/china-shunning-biggest-ore-shipsshows-2-3-billion-vale-mistake-freight.html>. Acesso 22/10/2014. 